\title{
Two variants of the Nutritional Risk in the Critically III Score as predictors of mortality in Intensive Care Unit patients at a Brazilian University Hospital
}

\section{Duas variantes do Escore de Risco Nutricional em Pacientes \\ Críticos como preditoras de mortalidade em pacientes \\ admitidos em uma Unidade de Terapia Intensiva \\ de um Hospital Universitário Brasileiro}

\author{
Amanda Forte dos Santos SILVA 1 (D) 0000-0003-2831-1743 \\ Audrey Machado dos REIS2 (iD) 0000-0003-2212-3709 \\ Julia MARCHETTI2 (D) 0000-0001-6122-0822 \\ Oellen Stuani FRANZOSI ${ }^{3}$ (ID) 0000-0002-5617-462X \\ Thais STEEMBURGO2 (iD) 0000-0003-3351-9901
}

\section{A B S T R A C T}

\section{Objective}

To evaluate the agreement between the modified version of the Nutritional Risk in the Critically III Score (without Interleukin-6) and a variant composed of C-Reactive Protein as well as its capacity to predict mortality.

\footnotetext{
$\overline{1}$ Universidade Federal do Rio Grande do Sul, Faculdade de Medicina, Departamento de Nutrição. Porto Alegre, RS, Brasil.

2 Universidade Federal do Rio Grande do Sul, Faculdade de Medicina, Programa de Pós-Graduação em Alimentação, Nutrição e Saúde. R. Ramiro Barcelos, 2400, $2^{\circ}$ andar, Santa Cecilia, 90035-003, Porto Alegre, RS, Brasil. Correspondence to: T. STEEMBURGO. E-mail: <tsteemburgo@gmail.com>.

${ }^{3}$ Universidade Federal do Rio Grande do Sul, Faculdade de Medicina, Programa de Pós-Graduação em Ciências Médicas. Porto Alegre, RS, Brasil.

Support: Fundo de Incentivo à Pesquisa do Hospital de Clínicas de Porto Alegre (Project approval number 17.0524) and Coordenação de Aperfeiçoamento de Pessoal de Nivel Superior.

Article elaborated from dissertation by AM REIS, entitled "Nutrition Risk In Critically Ill Score (NUTRIC): uso isolado e combinado com o Nutritional Risk Screening (NRS2002) na predição de mortalidade hospitalar de pacientes criticamente doentes". Universidade Federal do Rio Grande do Sul; 2019.
}

\section{How to cite this article}

Silva AFS, Reis AM, Marchetti J, Franzosi O, Steemburgo T. Two variants of the Nutritional Risk in the Critically Ill Score as predictors of mortality in Intensive Care Unit patients at a Brazilian University Hospital. Rev Nutr. 2020;33e190031. http://dx.doi.org/10.1590/1678-9865202033e190031 


\section{Methods}

A prospective cohort study was carried out with 315 patients in an Intensive Care Unit of a university hospital from October 2017 to April 2018. The agreement between the instruments was evaluated using the Kappa test. The predictive capacity for estimating mortality was assessed with the Receiver Operating Characteristic curve.

\section{Results}

The critical patients involved in the study had a mean age of $60.8 \pm 16.3$ years and $53.5 \%$ were female. Most patients had C-Reactive Protein levels $\geq 10 \mathrm{mg} / \mathrm{dL}(\mathrm{n}=263,83.5 \%)$ and their admission in the Intensive Care Unit was medical ( $n=219,69.5 \%)$. The prevalence of mortality was observed in $41.0 \%$ of the evaluated patients. The proportions at high nutritional risk according to Nutritional Risk in the Critically III without Interleukin-6 and with C-Reactive Protein were $57.5 \%$ and $55.6 \%$, respectively. The tools showed strong and significant agreement (Kappa $=0.935 ; p=0.020$ ) and satisfactory performances in predicting mortality (area under the curve 0.695 [0.636-0.754] and 0.699 [0.640-0.758]).

\section{Conclusion}

Both versions of the Nutritional Risk in the Critically III tool show a satisfactory agreement and performance as predictors of mortality in critically ill patients. Further analysis of this variant and the association between nutrition adequacy and mortality is needed.

Keywords: Critical illness. Intensive Care Unit. Nutritional assessment.

\section{R E S U M O}

\section{Objetivo}

Avaliar a concordância entre a versão modificada do Escore de Risco Nutricional em Pacientes Críticos (sem Interleucina-6) e uma variante composta de Proteína C-Reativa, bem como a capacidade de ambas as versões para predizer mortalidade em pacientes críticos.

\section{Métodos}

Trata-se de um estudo de coorte prospectivo em 315 pacientes admitidos em uma Unidade de Tratamento Intensivo de um hospital universitário brasileiro no período de outubro de 2017 a abril de 2018. A concordância entre os instrumentos foi avaliada pelo teste Kappa. A capacidade preditiva de mortalidade foi avaliada pela curva Receiver Operating Characteristic.

\section{Resultados}

Os pacientes apresentaram idade média de 60,8 8 16,3 anos, dos quais 53,5\% eram mulheres. A maioria dos pacientes apresentou níveis de Proteína C-Reativa $\geq 10 \mathrm{mg} / \mathrm{dL}$ ( $n=263 ; 83,5 \%$ ). O tipo de admissão na Unidade de Terepia Intensiva foi clínica $(n=219 ; 69,5 \%)$, sendo que a prevalência da mortalidade foi observada em $41,0 \%$ dos pacientes avaliados. O alto risco nutricional, avaliado pelo Nutritional Risk in the Critically III sem Interleucina-6 e pela variante com Proteína C-Reativa, foi demonstrado em 57,5\% e 55,6\% dos pacientes críticos, respectivamente. Os instrumentos demostraram concordância forte e significativa (Kappa=0,935; $p=0,020$ ) e desempenho satisfatório para predizer mortalidade (área sob a curva 0,695 [0,636-0,774] e 0,699 $[0,640-0,758])$.

\section{Conclusão}

Ambas as versões do Escore de Risco Nutricional em Pacientes Críticos apresentam boa concordância e desempenho satisfatório como preditores de mortalidade em pacientes críticos. É ainda necessária uma análise mais aprofundada desta variante, bem como da associação entre adequação nutricional e mortalidade.

Palavras-chave: Estado crítico. Unidade de Terapia Intensiva. Avaliação nutricional.

\section{INTRODUCTION}

Malnutrition is a common situation in hospitalized patients, highly frequent in critically ill patients [1], and it is associated with a higher risk of mortality, longer hospital stays, and consequently higher financial costs to health services [2]. In critically ill patients, acute disease severity and metabolic 
stress affect nutritional risk, which is also related to unfavorable outcomes in the patient's prognosis, such as poor healing, increased risk of nosocomial infections, and all-cause mortality [3]. The nutritional status is an important modifiable risk factor for clinical outcomes in critically ill patients [4] and its early identification is of great importance for the reduction of morbidity and mortality in this group of patients [3].

Many tools using a variety of criteria were created to identify nutritional risk [5,6]. However, these tools were developed for outpatients and/or hospitalized patients and are not specific for patients in the Intensive Care Unit (ICU), since they do not use ICU markers of disease severity and prognosis, and may classify all critically ill patients with high nutritional risk [6-8].

Heyland et al. [7] proposed a specific nutritional risk instrument for critically ill patients, the Nutrition Risk in Critical III Score (NUTRIC), which is based on a conceptual model of malnutrition development. This tool quantifies the risk of a patient developing adverse events that are potentially modifiable by early and aggressive nutritional interventions [7]. In addition, it is a method strongly recommended by the American Society of Parenteral and Enteral Nutrition [9]. In fact, this tool demonstrated that approximately $50 \%$ of patients admitted to the ICU have high nutritional risk [1]. Similar discoveries were described by a Brazilian study in which the prevalence of high nutritional risk was observed in 46\% of critically ill patients [10]. The Nutritional Risk Screening 2002 (NRS-2002) is also a nutritional screening tool that addresses traditional indicators of malnutrition, such as weight loss and reduced food intake; however, it was developed from randomized controlled trials conducted with hospitalized patients and it does not include ICU parameters [5]. More recently, a retrospective study demonstrated that NUTRIC is superior to the NRS-2002 protocol for assessing malnutrition risk in ICU patients [4]. Moreover, researchers have demonstrated that the high nutritional risk, identified by NUTRIC, is associated with clinical outcomes and death $[1,11]$.

Inflammatory markers, such as Interleukin-6 (IL-6) and C-Reactive Protein (CRP), are being studied and incorporated into the NUTRIC Score $[7,8]$ since inflammation is associated with a weakened immune state with increased chances of infection and longer hospital stays [12]. The studies are still scarce. Heyland et al. described the importance of the role of inflammation in the presence of malnutrition, expressed by IL-6 [7]. However, this biomarker is not a common variable in medical records and another cutoff was proposed in the absence of IL-6 [7]. On the other hand, a study conducted in critically ill patients using mechanical ventilation has shown that the addition of CRP improves the NUTRIC score performance and may be an alternative to IL-6 when it is not available [8].

Considering that nutritional risk in critically ill patients refers to the risk of developing complications associated with poor nutritional status [13] and the presence of malnutrition is high and frequently associated with increased mortality, the aim of this study was to evaluate the agreement between the modified version of the NUTRIC score (without IL-6) (NUTRIC-1) already validated and a variant of CRP (NUTRIC-2), as well as its ability to predict mortality in critically ill patients.

\section{METHODS}

A prospective cohort study was performed with critically ill patients admitted to the ICU of a university hospital in Brazil. The cohort included adult patients (age $\geq 18$ years-old) of both genders, admitted in the period between October 2017 and April 2018. Patients with advanced terminal illnesses, neurodegenerative diseases, therapeutic limitations, and pregnant women were excluded from the research. 
Patients were identified through daily screenings in a maximum period of 72 hours after the admittance to the ICU. They were accompanied until hospital discharge or death. All data used in this research was taken from physical and electronic records, from patients, assistant staff, family, and/or companions. No modifications in the patients' treatment were performed during the hospitalization period.

The study was conducted according to the guidelines of the Declaration of Helsinki and all procedures involving patients were approved by the Hospital Ethics Committee (protocol registration number 170524). All patients or their legally responsible person signed an informed consent form.

Clinical and demographic characteristics as diagnosis, age, gender, ethnicity, Body Mass Index (BMI), and CRP values were collected from electronic records. Other outcome measures included the Length of Stay (LOS) in the hospital (days), ICU LOS (days), ICU-free days, readmission at the $\mathrm{ICU}$, infection during hospitalization (according to the medical records), and death. The following infectious complications were considered: urinary, respiratory, and gastrointestinal tract, surgical wounds, central nervous system, and cutaneous infections. All outcomes were obtained from the medical records of each participant.

The inflammatory biomarker CRP was obtained through the electronic record within 72 hours of the patient's hospitalization in the ICU. C-Reactive Protein cutoff point $\geq 10 \mathrm{mg} / \mathrm{dL}$ was considered as suggested by the study by Moreti et al. [8]

The nutritional screening was performed by a trained nutritionist using the Nutrition Risk in the Critically III (NUTRIC) in a period of up to 72 hours after admission to the ICU [7]. The NUTRIC-1 score was calculated based on the patient's age, number of comorbidities, number of days at the hospital before ICU admission, Acute Physiology and Chronic Health Evaluation II (APACHE II), and Sequential Organ Failure Assessment (SOFA) scores [14]. The APACHE II score was obtained through axillary temperature, mean blood pressure, heart rate, respiratory rate, arterial oxygen partial pressure, and serum levels of leukocytes, creatinine, potassium, sodium, and hematocrit, besides age and diagnosis. The SOFA score was obtained with platelet count, serum total bilirubin, serum creatinine, mean blood pressure, vasopressor use, arterial oxygen partial pressure/inspired oxygen fraction ratio (PaO2/FiO2) [14]. The same variables were used for calculating the NUTRIC-2 score, adding one point when Us- CRP levels $\geq 10 \mathrm{mg} / \mathrm{dL}$ [8].

Data are presented as mean and standard deviation, median (P25-P75), or number (\%), and compared using $t$ Student, Mann-Whitney $U$, and $\chi^{2}$ tests, respectively. Patients were classified as high risk in the modified version (NUTRIC-1) when the score was $\geq 5-9$ points and in the proposed variant (NUTRIC-2) at $\geq 6-10$ points ( 1 point added when CRP $\geq 10 \mathrm{mg} / \mathrm{L}$ ).

The agreement between the screening tools was calculated with the Kappa coefficient. Kappa varies from 0 to 1: a value <0.2 indicates poor agreement; 0.2-0.4 fair agreement; 0.4-0.6 moderate agreement; 0.6-0.8 substantial agreement; and $>0.8$ almost perfect agreement [15]. The Receiver Operating Characteristic (ROC) curve was constructed by calculating the sensitivity and specificity; it was used to evaluate the performance of scores NUTRIC-1 and -2 to predict mortality.

The calculations were performed with the Statistical Package for The Social Sciences (SPSS) 23.0 (Chicago, IL, 2016) software [16], and p-values <0.05 were considered statistically significant.

"Screening nutrition instruments as outcomes of critical patients in clinical predictor" was a prospective cohort study, carried out at Hospital de Clínicas in Porto Alegre, approved by its Research 
Ethics Committee (registration number 170524), and it is in accordance with Resolution 466/12 of the National Health Council and the Declaration of Helsinki. All procedures with the participants were performed only after they signed the Informed Consent Form.

\section{R E S U L T S}

A total of 315 patients were included $(60.8 \pm 16.3$ years old, $53.3 \%$ female). A total of 181 (57.5\%) and $175(55.6 \%)$ critically ill patients were considered at high risk according to the NUTRIC-1 and NUTRIC-2 scores, respectively. The majority of the patients (84.0\%) were white and their mean BMI was $26.4 \pm 6.5 \mathrm{~kg} / \mathrm{m}^{2}$. With regards to disease severity, mean APACHE II score was $19.8 \pm 7.6$ and median SOFA score was 6.0 points (3.0-9.0). The median of the CRP was $81.8 \mathrm{mg} / \mathrm{dL}$ (22.9-175.5) and the majority of patients $(83.5 \%)$ had $C R P \geq 10 \mathrm{mg} / \mathrm{dL}$. In addition, more patients were admitted to the ICU with clinical diagnoses (69.5\%). The median hospital LOS was 18.0 days (11.0-32.0). At the ICU, the median LOS was 6.0 days (3.0-11.0), ICU-free days were 12.0 days (4.0-21.0), and $11.4 \%$ were readmitted to the ICU. Around $56.2 \%$ of the patients presented infections during the hospitalization period. The following infections were considered: respiratory tract $(26.0 \%)$, urinary tract $(14.3 \%)$, blood $(18.5 \%)$, cutaneous $(7.0 \%)$, surgical wound $(2.5 \%)$, gastrointestinal $(14.3 \%)$, and central nervous system (0.6\%). Among the patients admitted to the ICU, $41.0 \%$ died.

Table 1 describes the main clinical characteristics of critically ill patients - survivors $(n=186)$ and non-survivors ( $n=129)$. Non-survivors presented higher APACHE II and CRP levels when compared to survivors. Significant differences regarding hospital LOS among patients were also observed. In the nutritional risk assessment, we observed that survivors had a lower score according to the NUTRIC evaluation when compared to non-survivors. In fact, the prevalence of high nutritional risk assessed by NUTRIC 1 and 2 was demonstrated in non-survivors (approximately 55\%).

Table 1. Clinical characteristics of critically ill patients - survivors and non-survivors ( $n=315)$. Hospital de Clínicas de Porto Alegre, Brazil, 2017-2018.

\begin{tabular}{|c|c|c|c|}
\hline Clinical characteristics & Survivors ( $n=186$ ) & Non-survivors $(n=129)$ & $p$-value \\
\hline Age (years) ${ }^{1}$ & $58.1 \pm 16.6$ & $64.6 \pm 15.0$ & $0.278^{*}$ \\
\hline BMI $\left(\mathrm{kg} / \mathrm{m}^{2}\right)^{1}$ & $27.5 \pm 7.0$ & $24.8 \pm 5.4$ & $0.133^{*}$ \\
\hline APACHE II (score) ${ }^{1}$ & $18.0 \pm 6.3$ & $22.5 \pm 7.4$ & $0.001^{*}$ \\
\hline SOFA (score) $)^{2}$ & $5.0(2.0-8.0)$ & $7.0(4.0-11.0)$ & $<0.001^{* *}$ \\
\hline $\operatorname{CRP}(\mathrm{mg} / \mathrm{dl})^{2}$ & $68.7(17.2-146.6)$ & $103.4(38.6-205.8)$ & $0.005^{* *}$ \\
\hline Hospital LOS (days) ${ }^{2}$ & $20.0(14.7-33.2)$ & $14.0(8.0-30.0)$ & $0.001^{* *}$ \\
\hline ICU LOS (days) ${ }^{2}$ & $5.0(3.0-9.0)$ & $6.0(3.0-12.0)$ & $0.114^{* *}$ \\
\hline ICU FREE-DAYS 2 & $11.0(4.0-20.2)$ & $12.0(4.0-23.0)$ & $0.486^{* *}$ \\
\hline Readmission in ICU (yes) ${ }^{3}$ & $19(10.2 \%)$ & $17(13.2 \%)$ & $0.416^{* * *}$ \\
\hline Infection (yes) ${ }^{3}$ & $106(57.0 \%)$ & $71(55.0 \%)$ & $0.732^{* * *}$ \\
\hline NUTRIC-1 $1^{2, a}$ & $4.0(1.0-9.0)$ & $6.0(2.0-13.0)$ & $<0.001^{* *}$ \\
\hline Score $\geq 5-9$ points ${ }^{3, t}$ & $85(47.0 \%)$ & $96(53.0 \%)$ & $<0.001^{* * *}$ \\
\hline NUTRIC-2 $2^{2, b}$ & $5.0(2.0-10.0)$ & $7.0(2.0-14.0)$ & $<0.001^{* *}$ \\
\hline Score $\geq 6-10$ points $^{3,+}$ & $79(45.1 \%)$ & $96(55.0 \%)$ & $<0.001^{* * *}$ \\
\hline
\end{tabular}

Note: Data are presented as: ${ }^{*}:$ t Student Test; ${ }^{* *}$ : Mann-Whitney $U$ Test; ${ }^{* * *}: \chi^{2}$ test; ${ }^{\dagger}$ : Result considered as high nutritional risk; ${ }^{\text {a. Without }}$ Interleukin-6; ${ }^{\mathbf{b}}$ : Included C-Reactive Protein (mg/dL); ${ }^{1}$ : Mean and Standard Deviation; ${ }^{2}$ : Median (P25-P75); ${ }^{3}$ : Number and prevalence (\%). APACHE II: Acute Physiology and Chronic Health Evaluation II; BMI: Body Mass Index; CRP: C-Reactive Protein; ICU: Intensive Care Unit; LOS: Length of Stay; NUTRIC: Nutrition Risk in the Critically III; SOFA: Sequential Organ Failure Assessment. 
Association between high nutritional risk according to NUTRIC ( 1 and 2) and outcome measures are described in Table 2. Patients evaluated by NUTRIC-1 as with high nutritional risk had longer ICU stays and higher prevalence of death when compared to patients who presented nutritional risk $<5$ points. Patients evaluated by NUTRIC-2 as with high nutritional risk presented similar associations with prolonged ICU stays and death. No significant association was found between high nutritional risk assessed by NUTRIC- 1 and -2 and the hospital LOS, ICU-free days, readmission to ICU, and presence of infection.

When we constructed the ROC curve, sensitivity and specificity values demonstrated satisfactory performances in predicting mortality using NUTRIC-1 and NUTRIC-2 (Table 3). In addition, NUTRIC-1 and NUTRIC-2 instruments showed a strong and significant agreement (Kappa=0.935; $p=0.020$ ).

Table 2. Association between the presence of high nutritional risk according to NUTRIC (1 and 2) and outcome measures. Hospital de Clínicas de Porto Alegre, Brazil, 2017-2018.

\begin{tabular}{|c|c|c|c|c|c|c|}
\hline \multirow{2}{*}{ Outcomes } & \multicolumn{3}{|c|}{ NUTRIC-1 ${ }^{a}$} & \multicolumn{3}{|c|}{ NUTRIC- $2^{\mathbf{b}}$} \\
\hline & Score $<5-9$ points & Score $\geq 5-9$ points ${ }^{\dagger}$ & $p$-value & Score $<6-10$ points & Score $\geq 6-10$ points $^{\dagger}$ & $p$-value \\
\hline Hospital LOS (days) & $18.0(10.7-31.0)^{1}$ & $19.0(11.5-32.0)^{1}$ & $0.913^{*}$ & $5.0(3.0-9.0)^{1}$ & $18.0(11.0-32.0)^{1}$ & $0.835^{*}$ \\
\hline ICU LOS (days) & $5.0(3.0-9.0)^{1}$ & $7.0(4.0-11.0)^{1}$ & $0.002^{*}$ & $2.7(1.0-7.4)^{1}$ & $5.0(3.0-9.0)^{1}$ & $0.004^{*}$ \\
\hline ICU free-days (days) & $10.0(4.0-20.5)^{1}$ & $12.0(4.0-22.5)^{1}$ & $0.555^{*}$ & $10.5(4.0-21.0)^{1}$ & $12.0(4.0-22.0)^{1}$ & $0.688^{*}$ \\
\hline Readmission ICU (yes) & $16(44.4 \%)^{2}$ & $20(55.6 \%)^{2}$ & $0.806^{* *}$ & $17(47.2 \%)^{2}$ & $19(52.8 \%)^{2}$ & $0.722^{* *}$ \\
\hline Infection (yes) & $76(42.9 \%)^{2}$ & $101(57.1 \%)^{2}$ & $0.871^{* *}$ & $79(44.6 \%)^{2}$ & $99(55.4 \%)^{2}$ & $0.939^{* *}$ \\
\hline Death (yes) & $134(42.5 \%)^{2}$ & $181(57.5 \%)^{2}$ & $<0.001^{* *}$ & $140(44.4 \%)^{2}$ & $175(55.6 \%)^{2}$ & $<0.001^{* *}$ \\
\hline
\end{tabular}

Note: Data are presented as: ": Mann-Whitney U Test; ${ }^{* *}: \chi^{2}$ Test; 1 : Median (P25-P75); ${ }^{2}$ : Number and prevalence (\%); a: Without IL-6; b: Included C-Reactive Protein $(\mathrm{mg} / \mathrm{dL}) ;{ }^{\text {t: }}$ Results considered as high nutritional risk.

ICU: Intensive Care Unit; LOS: Length of Stay; NUTRIC: Nutrition Risk in the Critically III.

Table 3. Measures of performance of nutrition screening tools to predict mortality in patients in the Intensive Care Unit. Hospital de Clínicas de Porto Alegre, Brazil, 2017-2018.

\begin{tabular}{|c|c|c|c|}
\hline Nutrition screening tool & Sensitivity(\%) & Specificity(\%) & Performance (ROC-AUC) \\
\hline NUTRIC-1 ${ }^{a}$ & 74.4 & 45.7 & $0.695(0.636-0.754)$ \\
\hline NUTRIC $-2^{b}$ & 73.6 & 42.5 & $0.699(0.640-0.758)$ \\
\hline
\end{tabular}

Note: a: Without Interleukin-6; $\mathbf{b}$ : Included C-Reactive Protein.

AUC: Area Under the Curve; NUTRIC: Nutrition Risk in the Critically III; ROC: Receiver Operating Characteristic.

\section{DISCUSSION}

Considering the possible complications associated with poor nutritional status it is very relevant to identify ill patients' nutritional risk as soon as possible. Thus, our study aimed to analyze two variants of the NUTRIC tool, one without inflammatory biomarker (NUTRIC-1) and the other using PCR as an inflammatory biomarker (NUTRIC-2). We also evaluated the instruments' ability to predict patients' mortality.

Out of the 315 patients, the NUTRIC-1 tool classified $57.5 \%$ as having a high nutritional risk, while the NUTRIC-2 tool with PCR as inflammation biomarker pointed to $55.6 \%$. Non-survivors presented higher scores for APACHE II and SOFA, as well as higher CRP levels and length of hospital stays. 
Compared to survivors, non-surviving patients had less significant weight losses, perhaps because those patients had more severe conditions and therefore died earlier, possibly having received more fluids. Also, $53 \%$ and $55 \%$ of patients who died had a higher nutritional risk, according to NUTRIC-1 and -2 , respectively. In addition, ICU LOS and death were significantly associated with patients who presented high nutritional risk.

Some of our results are in agreement with those found by Moretti et al. [8] In this crosssectional study conducted in critically ill patients, it was shown that the highest APACHE II score, length of stays, and weight losses were significantly associated with a higher mortality risk [8]. Although the previous study described by Heyland et al. [7] demonstrated that CRP was not associated with mortality, or did not improve the model of the tool, Moretti et al. [8] showed that the addition of CRP improves score performance and may be an alternative to IL-6, when not available. More recently, Jeong et al. [17] demonstrated that there was no significant difference between NUTRIC scores with IL-6 and without IL-6 ( $p=0.45)$ in predicting 28-day mortality in patients with sepsis.

Unfortunately, in this record, it was not possible to evaluate IL-6. However, we observed the most of our patients ( $85 \%$ ) had CRP levels $\geq 10 \mathrm{mg} / \mathrm{dL}$. CRP is a sensitive inflammatory marker in the acute phase of the disease and more accessible in clinical practice, and it may be an alternative in the evaluation of critical patients with NUTRIC. The importance of inflammation and the severity/etiology of illness is well recognized in the characterization of malnutrition [18,19], as is its association with hospital length of stay [20]. Our results suggest that the nutritional risk assessed by the tools, with and without CRP, showed a significant and positive association with unfavorable clinical outcomes, such as longer hospitalization and death.

The ability of nutritional screening tools to predict morbidity and mortality was also evaluated in patients at an emergency service [15]. The four tools evaluated in this study, Malnutrition Universal Screening Tool (MUST), Malnutrition Screening Tool (MST), Simplified Nutrition Appetite Questionnaire (SNAQ), and Nutrition Risk Assessment-2002 (NRS-2002), demonstrated satisfactory performances identifying patients at nutritional risk. In addition, patients at nutritional risk showed higher risk of very long hospital stays as compared with those not at nutritional risk, independent of the tool applied [15].

Recently, Vries et al. [3] applied mNUTRIC (modified NUTRIC, excluding IL-6) and MUST scores in patients in a Dutch ICU, showing relations between mNUTRIC, mortality, and days of mechanical ventilation. NRS-2002 is a nutritional risk instrument more commonly used in hospitalized patients than in critically ill patients [5]. It is a practical tool to use, but it does not meet all the evaluation criteria within the NUTRIC instrument. However, a prospective study showed that the NRS-2002 tool classified all critical patients at high nutritional risk [4]. It is important to point out that the authors did not use the suggested cut-off points for critically ill patients ( $<3$ no risk, $\geq 3<5$ risk and $\geq 5$ high-risk) [9] that were recently evaluated and showed ability to distinguish between critically ill patients in terms of clinical characteristics and outcomes [21]. In this way, we can see the importance of performing nutritional screening in this population with suitable scores for critically ill patients.

The NUTRIC score has not been validated yet for use in Brazil. Rosa et al. [10] demonstrated that translation of NUTRIC Score from English into Portuguese following internationally accepted methodology has succeeded in achieving idiomatic, semantic, and conceptual equivalence between the original source and the version produced in Portuguese. In the study, the prevalence of nutritionally high-risk patients may be around $50 \%$ in Brazilian ICUs; however, it is a pilot study with a small sample size and in which the IL- 6 was not evaluated in the NUTRIC [10]. On the other hand, the 
study is relevant as the tool will include language and Brazilian cultural adaptations [10]. In fact, Portuguese-translated NUTRIC Score may be useful for detecting critically ill patients at risk in other Portuguese speaking countries and further validation work is warranted [10].

Our study also has its limitations. First, data for both scores were collected by one trained individual, whereas in a study comparing two diagnostic/prognostic models, blinded comparisons would be applied to prevent bias.

These analyzes were performed only in patients who were admitted to the ICU, and it was not possible to apply them to patients in the ward. More robust results can be provided by analyzes that take a larger number of patients into account. On the other hand, the clinical outcomes (presence of infection and incidence of death) were evaluated during the entire hospitalization period, not restricted to 28 days.

It is important to note that our analyzes included all patients hospitalized in the ICU, not only patients with mechanical ventilation. In addition, patients with different diseases and in various age groups were included, thus making the results relevant. Another limitation of this study is that we did not analyze data on nutritional adequacy, and this is important because NUTRIC identifies which patients benefit most from early and /or aggressive nutritional therapy. And this information is only attainable when evaluating nutritional data. The use of the NUTRIC score is taking on large dimensions in the hospital care due to its specificity for the population hospitalized in the ICU, being the only tool created for the screening of these patients. Thus, it is important to produce studies that evaluate this score, as well as studies that test its different variations as alternatives.

\section{CONCLUSION}

In this record, we conclude that the higher nutritional risks, as evaluated by NUTRIC-1 and -2, were associated with an increased risk of worse clinical outcomes during hospitalization, including death and length of stay in the ICU. Both versions of the NUTRIC tools ( 1 and 2 ) demonstrated a perfect agreement and satisfactory performance as predictors of mortality in critically ill patients. In addition, the tools demonstrated a similar performance in predicting mortality and a perfect agreement. In this sense, in the absence of CRP, NUTRIC is a good predictor of mortality in critically ill patients. Further analysis of this variant and association between nutrition adequacy and mortality is needed.

CONTRIBUTORS

AF SANTOS, AM REIS, J MARCHETTI, OS FRANZOSI, and T STEEMBURGO contributed to the conception of the manuscript, data collection and analysis, and manuscript writing. AM REIS and T STEEMBURGO contributed to manuscript revision.

\section{REFERE N CES}

1. Mendes R, Policarpo S, Fortuna P, Alves M, Virella D, Heyland DK et al. Nutritional risk assessment and cultural validation of the modified NUTRIC score in critically ill patients: a multicenter prospective cohort study. J Crit Care. 2017;37:45-9.

2. Correia MITD, Perman MI, Waitzberg DL. Hospital malnutrition in Latin America: a systematic review. Clin Nutr. 2017;36(4):958-97. 
3. Vries $\mathrm{CH}$, Koekkoek $\mathrm{K}$, Opdam MH, Blokland D, Zanten A. Nutritional assessment of critically ill patients: validation of the modified NUTRIC score. Eur J Clin Nutr. 2018;72:428-35.

4. Canales C, Elsayes A, Yeh DD, Belcher D, Nakayama A, McCarthy CM et al. Nutrition risk in critically ill versus the nutritional risk screening 2002: are they comparable for assessing risk of malnutrition in critically ill patients? J Parenter Enteral Nutr. 2019;43(1):81-7.

5. Kondrup J, Rasmussen HH, Hamberg O, Stanga Z. Nutritional risk screening (NRS 2002): a new method based on an analysis of controlled clinical trials. Clin Nutr. 2003;22(3):321-36.

6. Marcadenti A, Mendes LL, Rabito EI, Fink JDS, Silva FM. Nutritional Risk in Emergency-2017: a new simplified proposal for a nutrition screening tool. J Parenter Enteral Nutr. 2017;42(7):1168-76.

7. Heyland DK, Dhaliwal R, Jiang X, Day AG. Identifying critically ill patients who benefit the most from nutrition therapy: the development and initial validation of a novel risk assessment tool. Crit Care. 2011;15(6):R268. http://dx.doi.org/10.1186/cc10546

8. Moretti D, Bagilet DH, Buncuga M, Settecase CJ, Quaglino MB, Quintana R. Estudio de dos variantes de la puntuación de riesgo nutricional "NUTRIC" en pacientes criticos ventilados. Nutr Hosp. 2014;29(1):166-72.

9. McClave SA, Taylor BE, Martindale RG, Warren MM, Johnson DR, Braunschweig C et al. Guidelines for the provision and assessment of nutrition support therapy in the adult critically III patient: Society of Critical Care Medicine and American Society for Parenteral and Enteral Nutrition. J Parenter Enteral Nutr. 2016;40(2):159-211.

10. Rosa M, Heyland D, Fernandes D, Rabito E, Oliveira M, Marcadenti A. Translation and adaptation of the NUTRIC Score to identify critically ill patients who benefit the most from nutrition therapy. Clin Nutr Espen. 2016;14:31-6.

11. Özbilgin S, Hanci V, Ömür D, Özbilgin M, Tosun M, Yurtlu S et al. Morbidity and mortality predictivity of nutritional assessment tools in the postoperative care unit. Medicine. 2016;95(40):e5038. http://dx.doi. org/0.1097/MD.0000000000005038

12. Powers J, Samaan K. Malnutrition in the ICU Patient Population. Crit Care Nurs Clin N Am. 2014;26(2):227-42.

13. Kondrup J. Nutritional-risk scoring systems in the intensive care unit. Curr Opin Clin Nutr Metab Care. 2014;17(2):17782.

14. Landis JR, Koch GG. The measurement of observer agreement for categorical data. Biometrics. 1977;33:159-74.

15. Rabito El, Marcadenti A, Fink JS, Figueira L, Silva FM. Nutritional Risk Screening 2002, short nutritional assessment questionnaire, malnutrition screening tool, and malnutrition universal screening tool are good predictors of nutrition risk in an emergency service. Nutr Clin Pract. 2017;32(4):526-32.

16. International Business Machines Corporation. Statistical Package for Social Sciences. Version 23.0 [software]. Chicago: IBM; 2016.

17. Jeong D, Hong SB, Lim CM, Koh Y, Seo J, Kim Y et al. Comparison of accuracy of NUTRIC and modified NUTRIC scores in predicting 28-day mortality in patients with sepsis: a single center retrospective study. Nutrients. 2019;10(7).

18. White JV, Guenter P, Jensen G, Malone A, Schofield M. Consensus statement: Academy of Nutrition and Dietetics and American Society for Parenteral and Enteral Nutrition: characteristics recommended for the identification and documentation of adult malnutrition (undernutrition). J Parenter Enter Nutr. 2012;36(3):275-83.

19. Cederholm T, Bosaeus I, Barazzoni R, Bauer J, Van Gossum A, Klek S et al. Diagnostic criteria for malnutrition e an ESPEN consensus statement. Clin Nutr 2015;34(3):335-40.

20. Jeejeebhoy KN, Keller H, Gramlich L, Allard JP, Laporte M, Duerksen DR et al. Nutritional assessment: comparison of clinical assessment and objective variables for the prediction of length of hospital stay and readmission. Am J Clin Nutr. 2015;101(5):956-65.

21. Maciel LR, Franzosi OS, Nunes DS, Loss SH, Reis AM, Rubin B et al. Nutritional Risk Screening 2002 cut-off to identify high-risk is a good predictor of ICU mortality in critically III patients. Nutr Clin Pract. 2019;34(1):137-41. 